\title{
Improving care-seeking for facility-based health services in a rural, resource-limited setting: Effects and potential of an mHealth project
}

\author{
Ariel Higgins-Steele ${ }^{1, a, e}$, A. Camielle Noordam ${ }^{b, f}$, Jessica \\ Crawford $^{c}$, and Jean Christophe Fotso ${ }^{d}$ \\ a UNICEF, Kabul, Afghanistan \\ ${ }^{\mathrm{b}}$ Maastricht University, Maastricht, the Netherlands \\ ${ }^{c}$ VillageReach, Balaka, Malawi \\ ${ }^{\mathrm{d}}$ Concern Worldwide US, New York, USA \\ e With Concern Worldwide US, seconded to UNICEF, New York, USA during \\ the implementation and evaluation of the project \\ ${ }^{f}$ With UNICEF, New York, USA during the evaluation of the project
}

\section{Abstract}

The aim of this paper was to investigate the impact of a toll-free hotline and mobile messaging service on care-seeking behaviors. Due to the low uptake of the services, the treatment on the treated estimate is used. For maternal health, the intervention had a strong, positive impact on antenatal care initiation and skilled birth attendance. No effect was observed for postnatal check-ups, receiving the recommended four antenatal care visits and vitamin A uptake. A negative effect was observed on tetanus toxoid coverage. For child health, no change was seen in child immunization, and a significant decrease was observed for care-seeking for children with fever. Different factors are associated with care-seeking, which may explain in part the variations seen across care-seeking behaviors and possible influence of exogenous factors. Introduction of mHealth services for demand generation require attention to local health systems to ensure adequate supply and quality are available.

Keywords: mHealth; Care-seeking; Maternal health; Child health; Malawi

${ }^{1}$ Corresponding author

UNICEF Afghanistan

United Nations Office Complex in Afghanistan (UNOCA), Jalalabad Road, P.O. Box 54.

Email:ahiggins@unicef.org

Phone: +93 798507353 


\section{Résumé}

L'objectif de cet article est d'analyser l'impact sur les comportements de demande de soins, d'un projet mSanté consistant en un service de ligne téléphonique sans frais et de messagerie mobile. En raison de la faible utilisation, l'estimateur du traitement sur les traités est utilisé. L'intervention a eu un impact positif sur l'initiation aux soins prénataux et l'accouchement par un personnel qualifié. Aucun effet n'a été observé sur les consultations post-natales, le respect de quatre visites prénatales ou l'utilisation de la vitamine $A$. Un effet négatif a été observé dans la couverture antitétanique. Pour la santé infantile, aucun changement n'a été observé sur la vaccination, alors qu'une baisse significative est observée sur le traitement des enfants ayant souffert de la fièvre. Différent facteurs sont associés à la demande des soins, ce qui expliquerait en partie les variations observées dans les comportements de demande des soins. Pour l'introduction des services mSanté, une attention doit être portée au système de santé, afin de s'assurer que l'approvisionnement et la qualité des soins sont adéquats

Mots clés: mSanté; Demande de soins; Santé maternelle; Santé de l'enfant; Malawi

\section{Introduction}

In Malawi, despite a consistent reduction over the last two decades, infant and under-five mortality rates remain high (NSO and ICF Macro 20II; UNICEF 2013). Under-five mortality in Malawi was 71 per 1,000 live births in 2012, down from II 2 in 2010 and 234 in 1992 (UNICEF 2013). Maternal mortality on the other hand dropped only minimally, with the Millennium Development Goal target still about six times lower than the current level of around 675 maternal deaths per 100,000 live births (GoM 2010; Colbourn et al. 20I4; UN 20I3). While a package of effective, health facility and communitybased, interventions could significantly improve maternal and child health $(\mathrm{MCH})$ outcomes, uptake of these services remains low (Darmstadt et al. 2005). For example, less than half of pregnant women in Malawi receive the four recommended antenatal care
(ANC) visits and only $12 \%$ of women attend ANC within the first trimester of pregnancy. Also, nearly $30 \%$ of deliveries are not attended by a skilled birth attendant (SBA) and almost half of women do not receive postnatal care (PNC). And, nearly one third of children with symptoms of malaria or acute respiratory infections (ARI) are not taken to a health facility for advice or treatment (NSO and ICF Macro 20I I).

To accelerate progress towards improved $\mathrm{MCH}$ outcomes, global commitments and national efforts triggered the implementation of new strategies and innovative solutions in low-resource contexts (Darmstadt et al. 2013). One such strategy is the use of mobile phones to improve the delivery of health services, also referred to as mHealth. As mobile phone ownership in low- and middle-income countries has grown substantially in the last decade, its potential to improve health services by enabling faster modes of 
communication is widely recognized (Vital Wave Consulting 2008; Noordam et al. 20I I). Use of mobile phones - for example through two-way communication, voice messages and/or short message services (SMS) - can overcome persistent health system constraints across the continuum of care (Labrique et al. 2013). In low-resource settings, mHealth interventions targeting groups in the general population have shown the potential to improve adherence to treatment protocols, promote healthy behavior, increase utilization of health services, and increase access to health information (Cole-Lewis and Kershaw 2010; Gurman, Rubin and Roess 2012; Sloninsky and Mechael 2008).

To adopt mHealth strategies to increase the utilization of facility-based services requires measuring and understanding health-seeking behavior, while also acknowledging the challenges and shortcomings of health care delivery in resource-limited settings (Noordam et al. 20I5). Appropriate utilization of facility-based $\mathrm{MCH}$ services is not only linked to demand-side barriers, such as lack of knowledge and cost of those services, but also to supply-side barriers such as human resources and availability of medicines (Chopra et al. 2012). For example, care may be sought but appropriate treatment may not be provided (Diaz et al. 20/3). In Malawi, among other barriers, challenges linked to accessing services include long distances to facilities, poor perceptions of quality, and lack of human resources (Lohela, Campbell and Gabrysch 2012; Kambala et al. 20I I). Moreover, women and caregivers of young children lack access to health information for decision-making which leads to delays in seeking care (Geubbels 2006; Chibwana et al. 2009).

Previous studies have highlighted ways in which mHealth and health promotion can be successful in improving healthy behaviors, positively influencing timely care-seeking (Chib, van Velthoven and Car 2014; Jennings and Gagliardi 20I3). Strategies such as SMS to deliver health-related messages (Crawford et al. 20I3) and hotline systems to enable two-way communication between individuals and health workers, have helped overcome some of the challenges surrounding utilization of health facility-based services (Ivatury, Moore and Bloch 2009; Corker 2010). More specifically for Malawi, mHealth solutions have been limited largely to strengthening providerto-provider communications and data reporting. In two districts in Malawi, an intervention aimed at connecting community health workers and district level officials found that mHealth can aid in dissemination of new information down to the health worker level, improve reporting on service delivery data, and save time and money on transportation costs (Lemay et al. 20I2). Another study in Malawi reported on a mHealth pilot project designed to facilitate communications between community health workers and their supervisors through SMS. This study demonstrated that the SMS project improved communication systems for several common applications such as reporting patient adherence, queries to supervisors on complicated symptoms or other issues, requests for medicines, and emergency transport referrals (Mahmud 2010). MHealth services to share information between the health worker or health system and the individual have only been documented, 
yet not studied extensively in Malawi (Noordam et al, 2015). Despite its potential, recent reviews of mHealth projects in low-resource settings highlight poor evaluations for desired outcomes and impact of these projects (Chib et al, 2014; Earth Institute, 2010; Mechael 2009; Tamrat and Kachnowski 20I2), which includes effects on careseeking behaviors.

This paper analyzes data from a study using a pre-post-test design with a comparison group to examine changes in care-seeking behaviors among women and caregivers of young children after the implementation of an mHealth initiative. We investigate the impact of the intervention on facility-based careseeking for $\mathrm{MCH}$. These findings are important to further guide the integration of mobile technology into health services. The paper is part of a series analyzing the effectiveness of a hotline and text messaging service named Chipatala Cha Pa Foni (CCPF) or "health centre by phone", implemented between 20II and 2013 in the catchment areas of four health centers in Balaka district, Malawi. The purpose of these services was to inform women and caregivers on essential care and encourage appropriate care-seeking during pregnancy, childbirth and infancy.

\section{Data and Methods}

\section{Data}

This paper draws on the evaluation data of the CCPF project in Balaka district, Malawi. The project aimed to increase knowledge and behavior relating to recommended $\mathrm{MCH}$ homebased and facility-based care. The CCPF project included a toll-free hotline service providing protocol-based health information, advice and referrals. Users could access this service to seek advice and information regarding the illness of their child under the age of five. The project also included an automated and personalized tips \& reminders mobile messaging service, for which subscribers could opt-in, with a choice of two local languages. For those community members who did not have a mobile telephone, volunteers were selected from communities and provided with a mobile telephone as a way to provide access to them. Box I provides some examples of automated tips \& reminders messages sent to CCPF subscribers, which include women who signed up and received messages via a volunteer equipped with a phone for community use. The project was implemented between July 2011 and June 2013 in Balaka district, an area with some of the poorest $\mathrm{MCH}$ indicators in the country (Crawford 2013). The project is described in more detail in the second paper in this series by Larsen Cooper et al, under review. 
Box I. Examples of automated tips \& reminders messages

\section{Messages for pregnant women}

6 weeks: "When you and your family know that you are pregnant, a visit to ANC will help you understand everything you need to do to keep the baby healthy."

10 weeks: "The ANC is your partner in the pregnancy. It is important to go to all 4 of your visits to use the tablets that they have given to you."

20 weeks: "At ANC visits, you will have a Tetanus Toxoid (TT) vaccine during pregnancy, to stop you or your baby from getting tetanus, which is a serious infection."

32 weeks: "When you deliver at the hospital, the baby will get everything he needs to start life healthy. Make sure you have a plan to get to the hospital when it is time" "Baby can come anytime now. Do you have all you need for delivery packed in a bag? Pack napkins, cloths, baby soap, towels, basin and clothes for you."

4 I weeks: "Be sure to take your baby to the health center 6 weeks after delivery. Your baby will get checked and receive more immunizations."

\section{Messages for mothers for their infant}

I week: "Make sure your baby has its vaccination. In the first week, your baby should get polio vaccine by mouth and the BCG vaccine against TB by injection."

6 weeks: "This week your baby needs to receive 2 vaccines; OPV and DTP-HepBHib. She will receive these vaccines 2 more times. It is very important to protect your baby."

I I weeks: "Remember to have your baby sleep under a treated mosquito net every night to prevent malaria and take him to the clinic straight away if he has fever."

I4 weeks: "It is now time for the third and final dose of OPV and DTP-HepB-Hib vaccines for your baby. It is important that these are given 4 weeks apart."

17 weeks: "Prevent pneumonia by protecting your baby from breathing smoke from rubbish or cooking fires and tobacco. Get treatment immediately if baby has fast breathing."

The evaluation used a quasiexperimental design, with catchment areas of two health centers in the contiguous Ntcheu district as the control site. The control district was selected based on similar characteristics with the intervention site and since other districts either had dissimilar characteristics or had other $\mathrm{MCH}$ projects ongoing that may influence responses of participants. Once the health centers in the intervention and control sites were selected for the study, GIS information was used to map catchment areas of the health facilities and create a comprehensive list of villages in each of the catchment area. GIS information also provided mean distance from each village to the nearest health center (IKI 2013).

The core of the evaluation data consisted of cross-sectional baseline and end line household surveys conducted in June-July 201I and April-May 2013, respectively. Three questionnaires (household, woman and under-five) were developed, covering more than 30 $\mathrm{MCH}$ indicators largely drawn from the Multiple Indicators Cluster Survey (MICS) (IKI 20I3). As it is the rule, the 
same questionnaires were used at both baseline and end line, with the exception of an additional exposure module administered at end line only with questions referring the CCPF project which began after baseline data was collected. At baseline, a total of 2,840 women ( 1,119 in the control site and $I, 72 I$ in the intervention site) and 3,605 children under-five ( 1,385 in the control and 2,220 in the intervention) were surveyed. At end line, a total of 3,853 women (2,509 in the intervention) and 3,26 I children were surveyed. Based on the population size in the catchment area, it was determined during planning for the baseline that for statistical significance a minimum of 1,600 subjects was needed per group for the intervention area and a minimum of I,200 per group for the control.

\section{Variables of interest}

In this paper, we analyze the following aggregate and individual variables related to facility-based care for $\mathrm{MCH}$ :

- Facility-based maternal health care (for women who had a live birth in the last 18 months)

- Received the correct dosage of the tetanus toxoid (TT) vaccine during the last pregnancy

o Received a Vitamin A dose during the last pregnancy

- Received the recommended four antenatal care (ANC) consultations during the last pregnancy

- Started ANC in first trimester during the last pregnancy
- Gave the last birth under the supervision of a skilled birth attendant

- Received one postnatal care (PNC) check-up within 2 days of the last birth

- Facility-based child health care

- Child was fully immunized by first birthday (children aged 12-23 months)

- Child with symptoms of acute respiratory illness $(A R I)$ in the last two weeks preceding the survey sought care at facility

- Child with fever in the last two weeks preceding the survey sought care at facility

The control variables included well known confounders at the community, household, woman and child levels, the selection of which was guided by literature reviews. These variables, as can be seen in Tables I and 2, include at the household level, wealth status, number of under-five children, and ethnicity and religion of the head of household. At the woman level, these are age, marital status, education, and access to a personal phone. Child characteristics are age and sex. Finally, at the community (village) level, the analyses control for the mean distance to the nearest health center.

\section{Data analysis}

Descriptive and multivariate analyses are employed to quantity the impact of the intervention on the outcomes of interest. Firstly, we estimate the simple difference-in-difference (DID) as follows:

$$
D I D(Y)=\left(\bar{Y}_{I E}-\bar{Y}_{C E}\right)-\left(\bar{Y}_{I B}-\bar{Y}_{C B}\right)
$$


where $\bar{Y}_{I E}$ and $\bar{Y}_{C E}$ represent the average outcome at end line in the intervention site and control area, respectively, and $\bar{Y}_{I B}$ and $\bar{Y}_{C B}$ the average outcome at baseline in the intervention site and control area, respectively. Since this estimate compares the intervention and the control sites regardless of the use of the services offered by the project, it is to be interpreted as intention-to-treat (ITT) effect (Heckman 2005).

Secondly, to adjust for potential confounding variables we conduct multivariate DID defined as follows:

$\mathrm{Y}_{i v t}=\beta_{0}+\beta_{1} \mathrm{~T}_{\mathrm{v}}+\beta_{2} \mathrm{P}_{t}+\beta_{3}\left(\mathrm{~T}^{*} \mathrm{P}\right)_{v t}+$ $W^{\prime}{ }_{\text {ivt }} \Phi+X^{\prime}{ }_{v} \Pi+\varepsilon_{\text {ivt }}$

where $Y_{\text {ivt }}$ is the outcome measure for woman/child $i$, in village $v$, at time $t$. $T_{v}$ is a dummy variable taking the value I for individuals in treatment areas and 0 for individuals in control areas; $P_{t}$ is a dummy variable taking the value 0 for the baseline data and I for the endline data; $W_{\text {ivt }}$ is a vector of the controls at the household, women and child levels; $X$ is a village-level control variable; and $\varepsilon_{\text {ivt }}$ is the idiosyncratic error, clustered by health center catchment area.

Thirdly, we further analyze the data to assess the effect of the program on its users, applying the so-called "treatment effect on the treated" (TOT) model. This analysis is of specific importance, especially if the uptake of the intervention is not very high. The method uses instrumental variable analyses to construct a proper counterfactual - the women who would have used the services in control communities had they been offered (Angrist et al. 1996). More detailed information on the research
methodologies limitations can be found in the first paper of this series (Fotso et al. 2015a).

\section{Ethical clearance}

Ethical approval for the study was granted by the National Health Sciences Research Committee, Malawi Ministry of Health.

\section{Results}

\section{Sample characteristics}

Table I shows the characteristics of women interviewed at baseline in the intervention and comparison areas. The distribution of women by household wealth, number of children under the age of five years, education, marital status and age appears similar across the intervention and control communities. As can be seen, a majority of women were from households with one child under-five years of age; about threequarters of women had completed primary education; and more than $80 \%$ were in union. The mean distance to the nearest health facility was slightly shorter in the intervention site compared with the control area (4.4 km versus $5.7 \mathrm{~km}$ ). The distribution by ethnicity, religion and access to a mobile phone exhibits differences, with the control area dominated by the Ngoni ethnic group (77.3\%) and non-Catholic Christians (70.1\%), while the intervention site shows a seemingly more balanced distribution across the ethnic and religious groups. Access to phone was higher in the intervention area (32\%) than in control communities (22\%).

Table I also shows that the overall baseline and endline samples had similar characteristics. There are two noticeable exceptions. The proportion of women in union dropped slightly from an average 
of $86 \%$ at baseline to $75.6 \%$ at end line. of five are presented in Table 2 . As can Access to phone on the other hand, be seen, the distribution is similar across improved from around $28 \%$ to $31.5 \%$ the intervention and control groups at during the same period. The sex and age baseline, and between the baseline and of the sample of children under the age end line samples.

Table I. Percentage distribution of mothers/caretakers of children under 5 and pregnant women

\begin{tabular}{ll} 
Baseline & \\
\hline Control Intervention & End line
\end{tabular}

\section{Community level covariates}

$\begin{array}{llll}\text { Mean distance to the health center }(\mathrm{km}) & 5.7 & 4.4 & 4.8\end{array}$

\section{Household level covariates}

Wealth

Poor (Lowest 50\%)

56.6

53.0

55.3

Rich (Highest 50\%)

43.4

47.0

44.7

Number of under-5 children

0

I

$2+$

Ethnicity of the head of household

Lomwe

Ngoni

Yao

Others

Religion of the head of household

Catholic

Other Christian

Muslim

Other/No Religion

Woman-level covariates

Access to a phone

No

77.6

68.0

68.5

Yes

22.4

32.0

31.5

Education

None

Primary
29.5

52.3

I8.I

18.5

50.9

25.7

4.8 


\begin{tabular}{ll} 
Baseline & \\
\hline Control Intervention
\end{tabular}

End line

Secondary +

9.7

10.6

13.1

Marital status

Not in union

11.0

17.0

24.4

In union

89.0

83.0

75.6

Age in years

$<20$

10.6

II.3

16.0

20-29

57.2

53.9

41.7

$30+$

32.2

34.7

42.3

$\mathbf{N}$

1,119

I,72 I

3,853

Table 2. Percentage distribution of children under 5

\begin{tabular}{ll} 
Baseline & \\
\hline Control Intervention & End line
\end{tabular}

Age in months

$\begin{array}{llll}<12 & 25.4 & 23.2 & 24.1 \\ 12-23 & 21.2 & 19.7 & 22.7 \\ 24+ & 53.4 & 57.0 & 53.2\end{array}$

Sex

\begin{tabular}{llccc} 
& Male & 48.4 & 51.3 & 51.5 \\
& Female & 51.6 & 48.7 & 48.5 \\
$\mathbf{N}$ & & $\mathbf{1 , 3 6 5}$ & $\mathbf{2 , 2 2 0}$ & $\mathbf{3 , 2 6 I}$ \\
\hline
\end{tabular}

Table 3 shows that at end line, the awareness of the hotline was high in the intervention area, at around $77 \%$ among the total sample of 2,509 women. Among individuals who heard about the hotline $(\mathrm{N}=I, 929)$, less than $25 \%$ used the services, a proportion which represent about $18 \%$ of the total sample of women at end line. Awareness of the mobile messaging system was substantially lower, at $33.3 \%$, and use was estimated at $22.6 \%$. 
Table 3. Awareness and use of the services among women of child bearing age at end line

$\frac{\text { Intervention area }}{\text { Percentage } \quad N^{\prime}} \quad \begin{gathered}\text { Control area } \\ \text { Percentage } N^{\prime}\end{gathered}$

Awareness and use of the hotline services

Heard about the services

$\begin{array}{ll}76.9 & 2,509 \\ 23.8 & 1,929\end{array}$

2.8

Used the services

23.8

1,929

3.5

38

Awareness and use of the mobile messaging services

Heard about the services

2,509

0.4

1,344

Used the services

22.6

835

0.0

'Denominator of the percentage

\section{Effect of the intervention on care- seeking behavior for maternal health}

Table 4 shows the levels of the selected maternal health indicators at baseline and endline and across the intervention and control areas, as well as the resulted difference-in-difference, adjusted and unadjusted. Three variables - TT vaccine, skilled birth attendance (SBA) and vitamin A - had high coverage in both sites, while PNC, and to a lesser extent, ANC initiation in the first trimester of pregnancy, displayed a low coverage. The proportion of pregnancies which received the recommended four ANC visits, on the other hand, ranged from $55 \%$ to $64 \%$.

The unadjusted and adjusted DID results indicate that the intervention did not have any ITT effect on either of the indicators for facility-based maternal care, and as a result, did not affect the aggregate maternal health indicator. Given the low use of services (only 18\% of women used the services), the TOT model is a more appropriate approach, as it adjusts for the fact that some individuals in the intervention area did not use the services, and some others in the control area would not use the services even if offered. As Table 4 shows, the TOT model reveals a markedly different pattern. The intervention had a strong, positive impact on ANC initiation during the first trimester of pregnancy. While the increase between baseline and end line did not vary across the two areas (about 12 percentage points increase) hence a negligible DID, the focus on women who used the services reveals a strong impact of the intervention. The project also had a positive effect on SBA, despite a similar margin of increase (about 5 percentage points) across the control and the intervention sites as observed for ANC initiation.

At the other end of the scale, there is a negative TOT effect of CCPF on TT vaccine during pregnancy. The indicator remained almost unchanged in the intervention site, but declined by about 4.5 percentage points in the control 
African Population Studies Special Edition, 2015

area, yielding a positive though not statistically significant DID. Table 4 also shows an absence of TOT effect on
PNC check-up, receiving the recommended four ANC visits, and vitamin $\mathrm{A}$. 
African Population Studies Special Edition, 2015

Table 4. Intention to treat (ITT) and treatment on the treated (TOT) effects of the interventions on facility-based care for maternal health

\begin{tabular}{|c|c|c|c|c|c|c|c|}
\hline & & \multicolumn{3}{|c|}{ Descriptive analysis } & \multicolumn{2}{|c|}{ Multivariate analysis } & \multirow[b]{2}{*}{$\begin{array}{l}\text { Corresponding } \\
\text { sub-sample }\end{array}$} \\
\hline & & Baseline & End line & $\begin{array}{c}\text { ITT effect } \\
\text { (Difference } \\
\text { in } \\
\text { difference) }\end{array}$ & $\begin{array}{c}\text { ITT effect } \\
\text { (Difference } \\
\text { in } \\
\text { difference) }\end{array}$ & $\begin{array}{l}\text { TOT effect } \\
\text { (Difference } \\
\text { in } \\
\text { difference) }\end{array}$ & \\
\hline \multirow{2}{*}{$\begin{array}{l}\text { I. Received the correct dosage of } \\
\text { the TT vaccine during pregnancy }\end{array}$} & Intervention & $86.0 \%$ & $85.8 \%$ & \multirow{2}{*}{0.044} & \multirow{2}{*}{0.040} & \multirow{2}{*}{$-0.104 * *$} & \multirow{2}{*}{$\begin{array}{l}\text { Had a live birth in } \\
\text { last } 18 \text { months } \\
(\mathrm{N}=2,8 \mid 3)\end{array}$} \\
\hline & Control & $93.0 \%$ & $88.4 \%$ & & & & \\
\hline \multirow{2}{*}{$\begin{array}{l}\text { 2. Received a Vitamin A dose } \\
\text { during last pregnancy }\end{array}$} & Intervention & $72.9 \%$ & $71.5 \%$ & \multirow{2}{*}{0.068} & \multirow{2}{*}{0.069} & \multirow{2}{*}{0.083} & \multirow{2}{*}{ Same } \\
\hline & Control & $63.2 \%$ & $54.9 \%$ & & & & \\
\hline \multirow{2}{*}{$\begin{array}{l}\text { 3. Received the recommended } 4 \\
\text { ANC consultations }\end{array}$} & Intervention & $61.7 \%$ & $55.4 \%$ & \multirow{2}{*}{0.085} & \multirow{2}{*}{0.079} & \multirow{2}{*}{0.055} & \multirow{2}{*}{ Same } \\
\hline & Control & $61.9 \%$ & $63.8 \%$ & & & & \\
\hline \multirow{2}{*}{ 4. Started ANC in first trimester } & Intervention & $26.4 \%$ & $38.9 \%$ & \multirow{2}{*}{0.009} & \multirow{2}{*}{0.008} & \multirow{2}{*}{$0.444 * * *$} & \multirow{2}{*}{ Same } \\
\hline & Control & $20.6 \%$ & $32.3 \%$ & & & & \\
\hline \multirow{2}{*}{$\begin{array}{l}\text { 5. Gave birth under the supervision } \\
\text { of a skilled birth attendant }\end{array}$} & Intervention & $91.9 \%$ & $96.1 \%$ & \multirow{2}{*}{-0.010} & \multirow{2}{*}{-0.012} & \multirow{2}{*}{$0.110 * *$} & \multirow{2}{*}{ Same } \\
\hline & Control & $90.8 \%$ & $96.1 \%$ & & & & \\
\hline \multirow{2}{*}{$\begin{array}{l}\text { 6. Received one PNC check-up } \\
\text { within } 2 \text { days of birth }\end{array}$} & Intervention & $3.9 \%$ & $5.3 \%$ & \multirow{2}{*}{0.017} & \multirow{2}{*}{0.016} & \multirow{2}{*}{0.022} & \multirow{2}{*}{ Same } \\
\hline & Control & $5.7 \%$ & $5.4 \%$ & & & & \\
\hline \multirow{2}{*}{$\begin{array}{l}\text { Overall facility-based care for } \\
\text { maternal health }\end{array}$} & Intervention & $0.4 \%$ & $9.1 \%$ & \multirow{2}{*}{0.092} & \multirow{2}{*}{0.085} & & \\
\hline & Control & $0.0 \%$ & $-0.5 \%$ & & & 0.235 & \\
\hline
\end{tabular}

Statistical significance: ${ }^{*} \mathrm{p}<0.10,{ }^{*} \mathrm{p}<0.05, * * * \mathrm{p}<0.01$ 
Table 5. Intention to treat (ITT) and treatment on the treated (TOT) effects of the interventions on facility-based care for child health

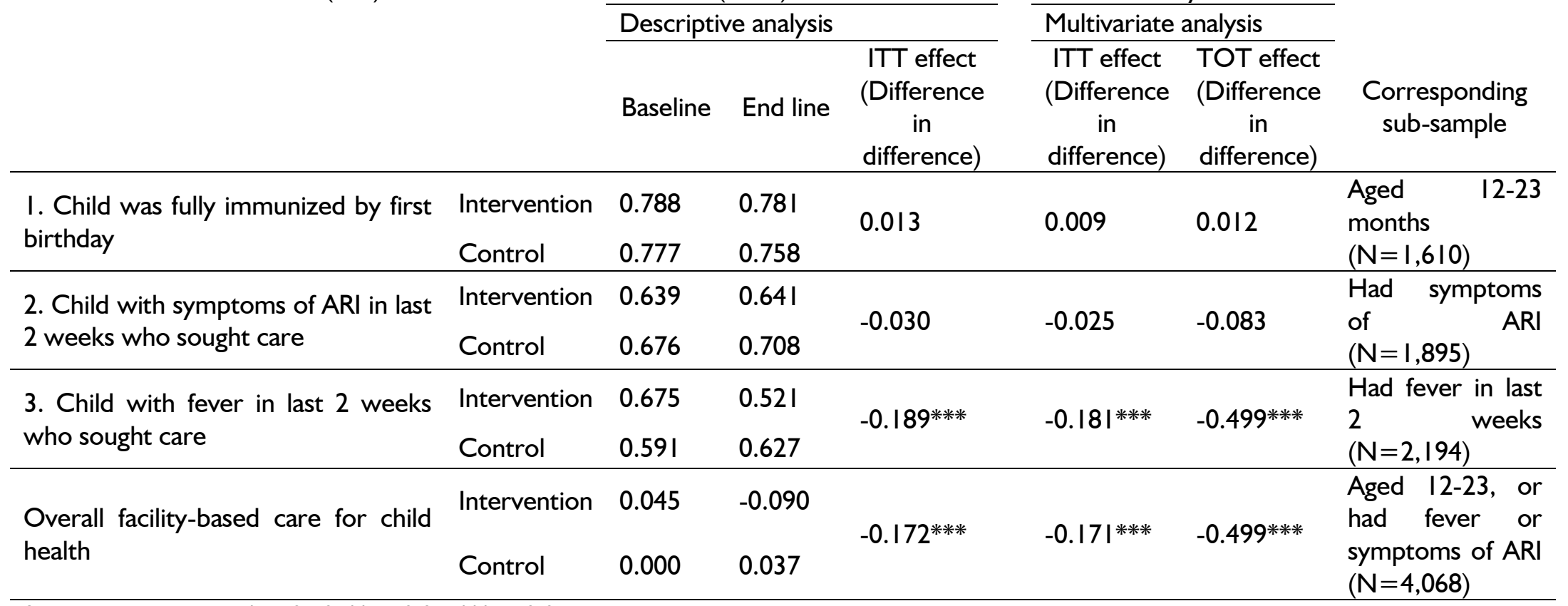




\section{Effect of the intervention on care- seeking behavior for child health}

The content of Table 5 which presents the results on child health is similar to that of Table 4.

Large, negative TOT effects are seen for the aggregate facility-based child health indicator $(p<0.01)$. This negative effect results exclusively from, and reflects, a reduction in the rate at which children with fever in the intervention communities sought treatment at a health facility. Indeed, the proportion of children with fever who visited a health facility dropped by 15.4 percentage points in the intervention site (from $67.5 \%$ to $52.1 \%$ ), and by contrast, increased by 3.6 percentage points in the control area (from $59.1 \%$ to $62.7 \%$ ), hence a DID of about 19 percentage points $(p<0.0 \mathrm{I})$.

The project did not have any ITT or TOT effect on the full immunization. Its coverage did not change noticeably over time, remaining at around $78 \%$ in the intervention group and at $77 \%$ in the control area. A similar pattern was observed for facility care for ARI symptoms.

\section{Discussion}

Characteristics between intervention and control samples are similar for household- and women-level covariates with the exceptions of ethnicity, religion and access to a mobile phone which show differences between groups sampled in Balaka and Ntcheu districts. It is noted elsewhere that differences in ethnicity and religion do not appear to affect $\mathrm{MCH}$ outcomes in Malawi (IKI 2013; Norad 2012).

\section{Utilization and access}

The overall use of the CCPF services was low; only $18 \%$ of the targeted population or less than $24 \%$ of those who were aware of the service used the hotline and the use of the tips \& reminders service was lower. A possible reason for the low uptake of the service may be access to a mobile phone in the household was less than one-third. For tips \& reminders, women may have been more inclined to use the hotline service via a community volunteer phone than to sign up for tips \& reminders on one of these shared phones. Importantly, the rural location of Malawi was selected, not in relation to mobile phone penetration, but because of poor $\mathrm{MCH}$ indicators that this pilot would seek to address. The pilot illustrates that even with enablers introduced by the pilot to increase access to the mHealth services - namely through community activities to enhance knowledge of the services and volunteers to facilitate access - use of the services was not widespread in the target groups.

Other studies confirm that uptake of new and potentially successful solutions aiming to improve access to health care and information can be low. Moreover, there is insufficient evidence on facilitators and barriers to the use of mobile phones for health-related needs (Chib, Wilkin and Hoefman 20II). Besides inadequate knowledge of how the new service works and what benefits are of using it (Marwa et al. 2013), reasons for non-use of mobile phones have been linked to privacy concerns and network coverage (Chib et al. 2012; Lepper et al. 2013).

Due to the low uptake of the CCPF project, its benefits can only be 
measured by assessing the impact on those who actually used the service, i.e., through a TOT model, a notable finding with implications for measurement of other mHealth projects.

\section{Maternal health}

The TOT model showed that, among the women who used the service, there was a significant increase in ANC initiation within the first trimester and SBA during delivery. ANC as well as SBA are crucial indicators for monitoring the wellbeing of the mother and child and ensuring timely identification of danger signs, birth preparedness as well as access to life-saving interventions when needed (Bhutta et al. 20/4). Yet, according to Malawi's Demographic and Health Survey (DHS 20I0), the majority of women start ANC late, only 12\% nationally (NSO and ICF Macro 20II) and $21-26 \%$ in our study area, attended ANC in the first trimester. SBA is much higher, nationally at around $71 \%$ and 91 $92 \%$ in our study area. Studies conducted in Malawi suggest that delays in ANC are (often) due to superstitious beliefs regarding the consequences of disclosing pregnancy in the first trimester (Pell et al. 2013; Banda 2013). Access to information through the hotline and tips \& reminders service may therefore have resulted in an increase in timely utilization of these services, either by providing information or facilitating referrals.

The intervention had no TOT effects on maternal indicators such as the use of Vitamin A, attending ANC at least four times during pregnancy and receiving PNC. In the long run, the increase in timely access to ANC might have a positive effect on these indicators, especially the use of Vitamin $A$ and attending all four ANC visits. This assumes regular and adequate stock of Vitamin A and health workers administering the supplement during an ANC visit. For PNC, national coverage in Malawi is $43 \%$, yet in our study area this was as low as 4-6\%. This large difference may be explained by variations in question phrasing between the DHS questionnaire and the Multiple Indicator Cluster Survey (MICS) indicator selected as part of this study. The PNC question for this study did not include home-based PNC visits, for example, and focused on how long after birth PNC was received. Even with these questionnaire differences, further research is needed to better understand why coverage of PNC is so low in the study area, whether this is due to structural reasons related to the local health system (e.g., lack of health resources) or associated with demand side barriers.

Finally, a negative effect was observed for women receiving TT vaccines. A decrease in TT coverage was found in both the intervention and control areas. While not specifically examined in this study, this could be related to limited availability of TT vaccines or health worker reluctance to vaccinate pregnant women. A study in Kenya suggests that improving access to ANC services is a necessary condition but not sufficient for improving uptake of TT immunization and suggests areas of future research to include the quality of provider-client interaction, availability of stocks of TT and women's perception of TT immunizations (Haile 20I3).

Overall, the CCPF project had a positive impact on maternal health indicators, which is important, as a combination of these interventions - and specifically increase in SBA - are needed 
to reduce the still high mortality rate in Malawi. If an increased proportion of women started ANC earlier, the health system could be strengthened to deliver other pregnancy-related interventions, such as to encourage repeat ANC visits to fulfil recommended four visits, Vitamin A supplementation and TT vaccination, and importantly encourage SBA. A multi-country study found significant and positive effect on the number of antenatal consultations on SBA during child birth (Adjiwanou and LeGrand 2013). Effective strategies, which not only include mobile phone use, need to be identified to ensure timely access to and supply of these and other essential services. Adjiwanou and LeGrand suggest SBA can be enhanced through improvements in quality of ANC, notably adequate information conveyed on the importance of SBA by the health care provider and provision of services closer to populations in need.

\section{Child health}

There was no TOT effect of the CCPF project on coverage of immunization and care-seeking for children with signs of ARI presumably because baseline values for both variables were relatively high. The percentage of children fully immunized in the study area was estimated at around $78 \%$, a figure comparable to the national estimate from the $2010 \mathrm{DHS}$. For care-seeking for ARI, the national coverage was around $70 \%$ as opposed to $65 \%$ in our study area. While vaccine coverage in Malawi has improved, children are often vaccinated at a later age. Reasons for this include that caregivers believe children were too young to be vaccinated (Minetti et al. 20/3), poor recognition of danger signs and illness severity, and financial considerations limiting timely access to care (Geldsetzer et al. 2014). For both the increase in coverage of vaccinations as well as the recognition of ARI, SMS services could inform caregivers about appropriate timing of vaccinations. Moreover, hotline services could potentially ensure timely referral for ARI, although this was an aim of CCPF and demonstrated negative effects.

Our findings show a negative effect of facility-based care-seeking for fever. Other studies show that children with fever in Malawi are often treated at home (Kazembe, Appeleton and Kleinschmid 2007; Holtz et al. 2003). According to Ministry of Health protocols, hotline workers only refer children with a fever to the nearest village clinic or health center for diagnosis and treatment if the fever is being presented as a danger sign and has persisted for seven days or if the fever is accompanied by other symptoms. It is possible that some children with a fever were appropriately treated at home and did not require a visit to a health facility. This is confirmed by findings on homebased care for the CCPF project, published in the third paper of this series (Fotso et al., 20l5b), suggesting that caregivers were well equipped to handle conditions like fever at home and avoid unnecessary trips to the facility.

\section{Conclusion}

When used by the targeted population, mHealth services providing the user options of how to access information on when and where to seek facility-based care have potential for behavior change. Changes were seen in a relatively short duration of this pilot, evaluated after less than two years after 
its introduction. Different factors are associated with care-seeking for outcome variables measured, which may explain in part the variations seen across care-seeking behaviors and possible influence of exogenous factors. mHealth can be a useful channel to improve careseeking, though reasonable expectations are required in terms of uptake and use by target groups, which can be low even with demand generation activities for the service, as well as of effects on demand for $\mathrm{MCH}$ services. Introduction of mHealth services for demand generation and information on careseeking require attention to local health systems to ensure adequate supply and quality are available.

\section{Acknowledgements}

The CCPF project is part of Innovations for Maternal, Newborn \& Child Health, an initiative of Concern Worldwide U.S. funded through a multiyear grant from the Bill \& Melinda Gates Foundation. The Government of Norway and the United Nations Foundation also supported the Malawi mHealth project (CCPF) through the Innovation Working Group Catalytic mHealth Grants program as part of the UN Secretary General's Every Women Every Child strategy. The project was implemented by VillageReach, an international NGO headquartered in Seattle, USA. We would like to give special thanks to the Reproductive Health Unit and its Director, Mrs. Fannie Kachale, and the Balaka District Health Office for their support of CCPF. The evaluation was conducted by Invest in Knowledge Initiative (IKI), a Malawibased research institution, with the leadership of Professor Susan Watkins of University of Pennsylvania and Dr.
Amanda Robinson of Ohio State University. The authors would like to thank Dr. Amanda Robinson for her contribution to data analysis, Dr. Linda Vesel of Concern Worldwide US for reviewing the manuscript, and the anonymous reviewers for their comments.

\section{Authors' Contributions}

AHS wrote the paper, conducted the literature review and contributed to the evaluation of the project. ACN wrote the paper and conducted the literature review. JC gave technical advice and edited the paper. JCF conducted the analyses, generated figures and wrote the paper. All authors commented on the manuscript at all stages and approved the final paper. .

\section{References}

Adjiwanou, V. and LeGrand, T. 2013. 'Does antenatal care matter in the use of skilled birth attendance in rural Africa: A multi-country analysis.' Social Science \& Medicine 86:26-34.

Angrist, J.D., Imbens, G.W. and Rubin, D,B. 1996. 'Identification of causal effects using instrumental variables.' Journal of the American Statistical Association 9l(434):444-455.

Banda, C.L. 20 I3. Barriers to utilization of focused antenatal care among pregnant women in Ntchisi district in Malawi. Available https://tampub.uta.fi/handle//0024/84 640 (accessed May 27 2014).

Bhutta, Z.A., Das, J.K., Bahl, R., Lawn, J.E., Salam, R.A., et al. 2014. 'Can available interventions end preventable deaths in mothers, newborn babies, and stillbirths, and at what cost?' The Lancet 384(9940):347-370. 
Chib, A., van Velthoven, M.H. and Car, J. 2014, 'mHealth Adoption in LowResource Environments: A Review of the Use of Mobile Healthcare in Developing Countries.' Journal of Health Communication 27:I-3I.

Chib, A., Wilkin, H., Ling, L.X., Hoefman, B. and Van Biejma, $H$. 2012. 'You Have an Important Message! Evaluating the Effectiveness of a Text Message HIV/AIDS Campaign in Northwest Uganda.' Journal of Health Communication 17 Supp I:I46-157.

Chib, A., Wilkin, H. and Hoefman, B. 20II. 'Vulnerabilities in mHealth implementation: a Ugandan HIV/AIDS SMS Campaign' Global Health Promotion 20(Suppl):26-32.

Chibwana, A.I., Mathanga, D.P., Chinkhumba, J. and Campbell, C.H. 2009. 'Socio-cultural predictors of health-seeking behaviour for febrile under-five children in Mwanza-Neno district, Malawi.' Malaria Journal 8:219.

Chopra, M., Sharkey, A., Dalmiya, N., Anthony, D. and Binkin, N. 2012. 'Strategies to improve health coverage and narrow the equity gap in child survival, health, and nutrition.' The Lancet 380(9850): I 33 |-40.

Colbourn, T., Lewycka, S., Nambiar, B., Anwar, I., Phoya, A. et al. 2013. 'Maternal mortality in Malawi, 197720I2.' BMJ Open 3:e004I50.

Cole-Lewis, H. and Kershaw, T. 2010. 'Text messaging as a tool for behavior change in disease prevention and management.' Epidemiol Rev 32:5669.

Corker, J. 2010. “'Ligne Verte” Toll-free hotline: Using cell phones to increase access to family planning information in the Democratic Republic of
Congo.' Cases in Public Health Communication \& Marketing 4:23-37.

Crawford, J., Larsen-Cooper, E., Jezman, Z., Cunningham, S.C. and Bancroft, E. 20I4. 'SMS versus voice messaging to deliver $\mathrm{MNCH}$ communication in rural Malawi: assessment of delivery success and user experience.' Global Health: Science and Practice doi: 10.9745/GHSP-D-13-00I 55.

Darmstadt, G.L., Marchant, T., Claeson, M., Brown, W., Morris, S., et al. 2013. A strategy for reducing maternal and newborn deaths by 2015 and beyond.' BMC Pregnancy and Childbirth 13:216.

Darmstadt, G.L., Bhutta, Z.A., Cousens, S., Adam, T., Walker, N., et al. 2005. 'Evidence-based, Cost-effective Interventions: How Many Newborn Babies Can We Save?' The Lancet 365(9463):977-88.

Diaz, T., George, A.S., Rao, S.R., Bangura, P.S., Baimba, J,B., et al. 2013. 'Healthcare seeking for diarrhoea, malaria and pneumonia among children in four poor rural districts in Sierra Leone in the context of free health care: Results of a cross-sectional survey.' BMC Public Health 13:157.

Earth Institute. 2010. Barriers and gaps affecting mHealth in low and middle income countries: A policy white paper. Washington DC: mHealth Alliance.

Fotso, J.C., Robinson, A.L., Noordam, A.C. and Crawford, J. 2015a. 'Fostering the use of quasiexperimental designs for evaluating public health interventions: Insights from an mHealth project in Malawi.' African Population Studies 29(I): 16071627.

Fotso, J.C., Bellhouse, L, Vesel, L, Jezman Z. 20I5b. 'Strengthening the 
home-to-facility continuum of newborn and child health care through mHealth: Findings from an intervention in rural Malawi.'African Population Studies 29(I): I663-1682.

Geldsetzer, P., Williams, T.C., Kirolos, A., Mitchell, S., Ratcliffe, L.A., et al. 2014. 'The recognition of and care seeking behaviour for childhood illness in developing countries: A systematic review.' PLoS ONE 9(4): e93427.

Geubbels, E. 2006. 'Epidemiology of maternal mortality in Malawi.' Malawi Medical Journal I8(4)208-228.

Government of Malawi (GoM). 2010. 2010 Malawi Millennium Development Goals Report. Lilongwe, Malawi.

Haile, Z.T., Chertok, I.R. and Teweldeberhan, A.K. 2013. 'Determinants of utilization of sufficient tetanus toxoid immunization during pregnancy: Evidence from the Kenya Demographic and Health Survey, 2008-2009' Journal of Community Health 38:(3):492-9.

Heckman, J,J. 2005. 'The Scientific model of causality.' Sociological Methodology 35(I): I-97.

Holtz, T.H., Kachur, S.P., Marum, L.H., Mkandala, C., Chizani, N., et al. 2003. 'Care seeking behaviour and treatment of febrile illness in children aged less than five years: a household survey in Blantyre District, Malawi.' Transactions of the Royal Society of Tropical Medicine and Hygiene 97(5):491-7.

Invest in Knowledge (IKI). 20I3. IKI's Evaluation Report of ICT for $\mathrm{MNCH}$ available at: http://innovationsformnch.org/knowl edge-center-resources/iki-evaluationreport-of-ict-for-mnch (accessed May 27 20l4).

Ivatury, G., Moore, J. and Bloch, A.
2009. 'A Doctor in your pocket: Health hotlines in developing countries.' Innovations: Technology, Governance, Globalization. 2009; 4(I): I19-153.

Jennings, L. and Gagliardi, L. 2013. 'Influence of mhealth interventions on gender relations in developing countries: A systematic review.' International Journal for Equity in Health 12:85.

Kambala, C., Morse, T., Masangwi, S. and Mitunda, P. 20II. 'Barriers to maternal health service use in Chikhwawa, Southern Malawi.' Malawi Medical Journal; 23(I): I-5.

Kazembe, L.N., Appeleton, C.C. and Kleinschmid, I. 2007. 'Choice of treatment for fever at household level in Malawi: examining spatial patterns.' Malaria Journal 6:40.

Labrique, A.B., Vasudevan, L., Kochi, E., Fabricant, R. and Mehl, G. 2013. 'mHealth innovations as health system strengthening tools: 12 common applications and a visual framework.' Global Health: Science and Practice doi: 10.9745/GHSP-D|3-0003 | .

Larsen-Cooper E, Bancroft E, O'Toole $M$, Jezman $Z$. 'Where there is no phone: Extending the reach of $\mathrm{mHealth}$ to individuals without personal phones in Balaka District, Malawi.' Under review.

Lemay, N., Sullivan, T., Jumbe, B. and Perry C.P. 2012. 'Reaching Remote Health Workers in Malawi: Baseline Assessment of a Pilot mHealth Intervention.' Journal of Health Communication I7suppl I:I05-II7.

Lepper, A.M., Eijkemans, M.J., van Beijma, H., Loggers, J.W., Tuijn C.L., et al. 2013. 'Response patterns to interactive SMS health education quizzes at two sites in Uganda: a 
cohort study' Tropical Medicine and International Health 18(4):5I6-52I.

Lohela, T.J., Campbell, O.M.R. and Gabrysch, S. 2012. 'Distance to care, facility delivery and early neonatal mortality in Malawi and Zambia.' PLoS ONE 7(I2): e52II0.

Mahmud, N., Rodriguez, J. and Nesbit, J. 2010. 'A text message-based intervention to bridge the healthcare communication gap in the rural developing world.' Technology and Health Care 18(3):I37-I44.

Marwa, B., Njau, B., Kessy, J. and Mushi D. 2013. 'Feasibility of introducing compulsory community health fund in low resource countries: views from the communities in Liwale district of Tanzania.' BMC Health Services Research 13:298.

Mechael, P.N. 2009. 'The case for mHealth in developing countries.' Innovations, Technology, Governance and Globalization 4(I): I03-I I8.

Minetti, A., Kagoli, M., Katsulukuta, A., Huerga, H., Featherstone, A., et al. 2013. 'Lessons and challenges for measles control from unexpected large outbreak, Malawi.' Emerging Infectious Diseases 19(2).

National Statistical Office (NSO) and ICF Macro. 201I. Malawi Demographic and Health Survey 2010. Zomba, Malawi, and Calverton, Maryland, USA: NSO and ICF Macro.

NORAD Evaluations Department. 2012. Local perceptions, participation and accountability in Malawi's Health Sector. Oslo, Norway.

Noordam, A.C., Kuepper, B.M., Stekelenburg, J. and Milen, A. 20II. 'Improvement of maternal health services through the use of mobile phones.' Tropical Medicine \& International Health 16(5):622-6.
Noordam, A.C., George, A., Sharkey, A.B., Jafarli, A., Bakshi, S.S, and Kim, J.C. 2015. 'Assessing scale up of mHealth innovations based on intervention complexity: Two case studies of child health programmes in Malawi and Zambia.' Journal of Health Communication 0: I-II.

Pell, C., Meñaca, A., Were, F., Afrah, N.A. Chatio S. et al. 2013. 'Factors Affecting Antenatal Care Attendance: Results from Qualitative Studies in Ghana, Kenya and Malawi.' PLoS ONE 8(I): e53747.

Sloninsky, D. and Mechael, P.N. 2008. Towards the development of an mhealth strategy: A literary review. New York, USA: World Health Organization and Earth Institute.

Tamrat, T. and Kachnowski, S. $20 / 2$. 'Special delivery: An analysis of mHealth in maternal and newborn health programs and their outcomes around the world.' Maternal Child Health Journal 16(5): 1092-1 I0I.

Gurman T.A., Rubin, S.E. and Roess A.A. 2012. 'Effectiveness of mHealth Behavior Change Communication Interventions in developing Countries: A Systematic Review of the Literature.' Journal of Health Communication 17: Suppl I:82-104.

United Nations Children's Fund (UNICEF). 2013. Committing to child survival: A promise renewed progress report 2013. UNICEF, New York.

United Nations (UN). 2013. The Millennium Development Goals Report 2013. United Nations, New York.

Vital Wave Consulting. 2008. mHealth in the global south: Landscape analysis. Washington D.C. and Bershire, UK: Vodafone Foundation - United Nations Foundations Partnership. 